\title{
PoLítICAS EDUCACIONAIS INCLUSIVAS EM TEMPOS NEOLIBERAIS: 0 DITO, O NÃO DITO E O MAL DITO
}

\author{
ERIKA MARINHO WITEZE ${ }^{1}$
}

RÉGIS HENRIQUe dos REIS SILVA²

\begin{abstract}
RESUMO: Este artigo analisa as bases legais e ideológicas das políticas educacionais inclusivas implementadas a partir da década de 1990 no Brasil. A partir de uma discussão sobre os desafios enfrentados pelo sistema educacional brasileiro no atendimento a alunos com deficiências, transtornos globais de desenvolvimento e altas habilidades/superdotação na atualidade, veremos quais as possibilidades e limites do discurso em defesa da diversidade no contexto neoliberal. Recorrendo às orientações trazidas pela Política Nacional de Educação Especial na Perspectiva da Educação Inclusiva e pelo mais recente Plano Nacional de Educação (2014-2024), problematizaremos o alinhamento da educação especial inclusiva com as teorias pedagógicas pós-modernas, bem como o acirramento dos processos de exclusão e marginalização de alunos com necessidades educacionais especiais dentro e fora da escola. Ademais, veremos como a transformação da inclusão em argumento do senso comum inibe as potencialidades emancipadoras e humanizadoras da educação, abordando as contribuições trazidas pela pedagogia histórico-crítica e pela teoria histórico-cultural.

Palavras-chave: Políticas inclusivas. Educação especial. Neoliberalismo.
\end{abstract}

INCLUSIVE EDUCATION POLITCS IN NEOLIBERAL TIMES: THE TOLD, THE NOT TOLD AND EVIL TOLD

ABSTRACT: This paper analyzes the legal and ideological foundations of inclusive educational policies implemented from the 1990s in Brazil. It begins debating the challenges faced today by the Brazilian educational system to assist students with disabilities, global development disorders and high skills / giftedness. From that we will see what are the possibilities and limits of speech in defense of diversity in the neoliberal context. We will use the guidelines brought by the National Policy on Special Education in the Perspective of Inclusive Education and the most recent National Education Plan (20142024) to question the alignment of inclusive special education with postmodern pedagogical theories, as well as the intensification of the processes of exclusion and marginalization of students with educational special needs in and out of school. Moreover, we will see how the transformation of inclusion in a common sense argument inhibits the emancipatory and humanizing potential of education, drawing on contributions from the historical-critical pedagogy and the cultural-historical theory. Keywords: Inclusive policies. Special education. Neoliberalism.

\footnotetext{
${ }^{1}$ Mestre em Educação pela Universidade Federal de Goiás - UFG. erikawiteze@gmail.com

2 Doutor em Educação. Docente da Universidade Estadual de Campinas - UNICAMP.
} 


\section{POLÍTICAS DE EDUCACIÓN INCLUSIVA EN TIEMPOS NEOLIBERALES: LO DICHO, LO NO DICHO Y LO MAL DICHO}

RESUMEN: Este artículo analiza los fundamentos jurídicos e ideológicos de las políticas educativas inclusivas implementadas desde la década de 1990 en Brasil. A partir de un análisis de los desafíos que hoy enfrenta el sistema educacional brasileño en el servicio a los estudiantes con discapacidades, trastornos globales del desarrollo y altas habilidades / superdotación, veremos cuáles son las posibilidades y los límites del discurso en defensa de la diversidad en el contexto neoliberal. Nosotros usaremos las directrices presentadas por la Política Nacional de Educación Especial en la Perspectiva de la Educación Inclusiva y el último Plan Nacional de Educación (2014-2024) para discutir la alineación de la educación especial inclusiva con las teorías pedagógicas posmodernas, así como la intensificación de los procesos de exclusión y marginación de los estudiantes con necesidades educacionales especiales dentro y fuera de la escuela. Por otra parte, vamos a ver como la transformación de la inclusión en un argumento de sentido común inhibe el potencial emancipatorio y humanizador de la educación, abordando las aportaciones de la pedagogía histórico-crítica y de la teoría histórico-cultural.

Palabras clave: Políticas de inclusión. Educación especial. Neoliberalismo.

\section{Introdução}

O objetivo deste artigo é problematizar sobre o dito, o não dito e o mal dito sobre as políticas educacionais inclusivas em tempos neoliberais. Partindo de uma análise dos dados fornecidos pelo Instituto Brasileiro de Geografia e Estatística (IBGE), pelo Ministério da Educação (MEC) e pelo Instituto Nacional de Estudos e Pesquisas Anísio Teixeira (INEP), analisaremos os desafios enfrentados pelos estabelecimentos educacionais brasileiros no atendimento ao público-alvo da educação especial³, tendo como ponto de ancoragem a Política Nacional de Educação Especial na Perspectiva da Educação Inclusiva (BRASIL, 2008) e a Meta 4 do atual Plano Nacional de Educação (PNE), instituído pela Lei 13.005/2014 (BRASIL, 2014).

O nivelamento da proposta inclusiva com as ações implementadas no âmbito da reforma do estado se intensifica a partir da década de 1990 no Brasil. Nesse período, o setor educacional passa a ser considerado um dos principais núcleos de investimentos de agências multilaterais, que recomendam a extensão da oferta do ensino elementar a todas as crianças, jovens e adultos com a finalidade de desenvolver competências/habilidades necessárias à inserção desses sujeitos no mundo do trabaIho (FONSECA, 2002; KUENZER, 2000).

De acordo com Shiroma, Moraes e Evangelista (2011), são evidentes as articulações entre as

\footnotetext{
${ }^{3}$ Utilizaremos neste trabalho a definição público-alvo da educação especial citada na Política Nacional de Educação Especial na Perspectiva da Educação Inclusiva (BRASIL, 2008), no Parecer CNE/CEB no 13 de 03 junho de 2009, no Decreto 7.611 de 17 de novembro de 2011, na LDBEN (BRASIL, 1996), com redação alterada pela Lei 12.796 de 04 de abril de 2013. Outro termo utilizado ao longo do artigo será pessoa com necessidades educacionais especiais (NEEs), denominação presente na legislação específica e em estudos/pesquisas mais recentes no campo da educação especial inclusiva.
} 
reformas implementadas pelos governos brasileiros do período e as recomendações dos organismos multilaterais. De fato, há uma profusão de parcerias do Estado com empresas, entidades da sociedade civil e organizações internacionais como o Banco Mundial (BM), o Banco Interamericano de Desenvolvimento (BID), a Comissão Econômica para América Latina e Caribe (Cepal), a Organização das Nações Unidas para a Educação, a Ciência e a Cultura (Unesco), a Organização dos Estados Americanos (OEA) e a Organização dos Estados Iberoamericanos - responsáveis pela disseminação de orientações que vinculam educação, desenvolvimento social e crescimento econômico.

A Conferência Mundial de Educação para Todos (UNESCO, 1990), defende a garantia de educação básica de qualidade para crianças, jovens e adultos. A partir de sete estratégias fundamentais, estabeleceu seis metas a serem executadas durante o decênio, relativas ao acesso universal ao ensino fundamental; à melhoria dos resultados de aprendizagem; à redução das taxas de analfabetismo; à promoção da equidade; e ao cultivo de competências, valores e capacidades úteis ao desenvolvimento produtivo e sustentável da sociedade. Propõe, assim, a utilização de ações eficientes de ampliação da oferta da educação básica, com vistas a atender a população que, historicamente, estava à margem do sistema educacional (MICHELS, 2006, SAVIANI, 2011).

Como resultado da Conferência Mundial sobre Necessidades Educacionais Especiais, a Declaração de Salamanca (UNESCO, 1994) trata especificamente de princípios, políticas e práticas no campo do ensino especial. O documento tem como meta a construção de uma "escola para todos", que ofereça condições de aprendizagem efetiva aos alunos com deficiências e outros distúrbios, inseridos nas escolas regulares. Tal proposição foi anunciada como uma "estratégia educacional global", expressando uma "focalização da política educacional, direcionada ao contingente de sujeitos que ou não vinham tendo acesso à escola ou nela não conseguiam permanecer por conta de suas diferenças individuais" (GARCIA, 2004, p. 73), que são tratadas agora como "necessidades especiais".

As conferências internacionais promovidas por agências multilaterais impactaram diretamente os países periféricos em suas proposições internas (KASSAR, 2011), o que contribuiu para a disseminação do discurso neoliberal, fundamentado sobre princípios ideológicos como a "igualdade de oportunidades", a inserção produtiva no mercado de trabalho e o progresso "social" vinculado à universalização do ensino básico. Consubstanciadas em teorias educacionais de base economicista e enfoque multiculturalista (MARSIGLIA, 2012; SILVA, 2014), a Carta de Jomtien e a Declaração de Salamanca sustentaram, assim, a elaboração de políticas compensatórias no âmbito da reforma do Estado brasileiro, implementadas ao longo da década de 1990 (SILVA, 2014). Como resultado, a educação, além um direito fundamental, torna-se um componente estratégico na formação de uma cultura da modernidade, particularmente útil à manutenção e reprodução do capitalismo. 
A partir dos argumentos supracitados e das reflexões que serão construídas ao longo do texto, veremos como a preocupação superficial com a inserção de todos os estudantes na escola regular contribui para o acirramento das disparidades no acesso ao conhecimento elaborado (BARROCO, 2011; MARSIGLIA, 2012) dialogando com os conceitos de inclusão excludente (KUENZER, 2005) e exclusão branda ${ }^{4}$ (FREITAS, 2002). Nessa perspectiva, examinaremos como os slogans em defesa da diversidade contribuem para a ocultação das desigualdades decorrentes do modo de produção capitalista - tensão expressa na dialética inclusão/exclusão, problematizada por Freitas et al. (2004) e Michels (2006). Questionaremos, assim, as finalidades às quais a educação especial na perspectiva inclusiva tem se prestado no contexto capitalista. Veremos também em que medida o discurso em defesa das diferenças promove e legitima estratégias de ocultação das desigualdades sociais.

Por fim, apoiados nas reflexões engendradas pela pedagogia histórico-crítica e pela teoria histórico-cultural, problematizaremos as contradições decorrentes da disseminação de teorias pedagógicas pós-modernas (de base multiculturalista, relativista e pragmatista); o esvaziamento da ação político-pedagógica em seu sentido mais amplo; e a ruptura em relação às várias formas de marginalização e discriminação, a que estão sujeitas as pessoas com necessidades educacionais especiais em sua incursão na escola regular.

\section{Políticas Educacionais Inclusivas (O Dito e o Não Dito)}

A Política Nacional de Educação Especial na Perspectiva da Educação Inclusiva (BRASIL, 2008) se situa dentro do movimento mundial pela educação inclusiva, que constitui um paradigma educacional fundamentado na concepção de direitos humanos, na indissociabilidade entre igualdade/diferença e na superação da exclusão dentro e fora da escola (GARCIA; MICHELS, 2011). A partir de uma análise preliminar da história da educação especial no Brasil, que abarca a trajetória das políticas públicas na área e um diagnóstico da situação atual (com base em dados do Censo Escolar e indicadores agrupados por nível/modalidade de ensino), o documento propõe uma ruptura em relação ao modelo integracionista, a partir da proposição de uma série de metas e diretrizes.

Ainda no texto da política, a educação especial é definida como modalidade de ensino que perpassa todos os níveis e etapas da escolarização, realiza o Atendimento Educacional Especializado (AEE) e disponibiliza os recursos/serviços a serem ofertados no ensino regular (BRASIL, 2008). O AEE,

\footnotetext{
4 "[...] ou seja, a estratégia de criação de trilhas de progressão continuada diferenciadas no interior da própria escola, alterando o 'metabolismo do sistema escolar' de forma a reforçar práticas de interiorização da exclusão" (FREITAS, 2002, p. 304, grifos do autor).
} 
por sua vez, refere-se às ações complementares (no caso dos estudantes com deficiências e/ou transtornos globais de desenvolvimento) e suplementar (no caso dos alunos com altas habilidades/superdotação) realizadas fora da sala de aula comum, considerando as necessidades específicas do públicoalvo da educação especial.

$\mathrm{Na}$ atualidade, as ações no campo das políticas de inclusão estão sob a responsabilidade da Secretaria de Educação Continuada, Alfabetização, Diversidade e Inclusão (SECADI) ${ }^{5}$ que, em articulação com os sistemas de ensino, implementa projetos/programas nas áreas de alfabetização e educação de jovens e adultos, educação ambiental, educação em direitos humanos, educação especial, educação do campo, educação escolar indígena, educação quilombola e educação para as relações étnico raciais 6 .

De acordo com Bezerra (2013), a atual configuração da SECADI decorre da sobreposição dos Decretos $n^{\circ}$ 7.480/2011, 7.688/2012 e 7.690/2012. Hoje, ela está estruturalmente dividida em: 1. Diretoria de Políticas de Educação do Campo, Indígena e para as Relações Étnico Raciais; 2. Diretoria de Políticas de Alfabetização e Educação de Jovens e Adultos; 3. Diretoria de Políticas de Educação em Direitos Humanos e Cidadania; 4. Diretoria de Políticas de Educação Especial; 5. Diretoria de Políticas de Educação para a Juventude (BEZERRA, 2013).

Esse autor faz uma crítica contundente ao caráter multiculturalista da SECADI, que fundamentada no pragmatismo gerencial, propõe o entrecruzamento de projetos ambíguos e demasiadamente vastos, fundamentados no, já esvaziado, discurso em defesa das diferenças. Outro problema, diz respeito ao papel secundário ocupado pelas políticas inclusivas voltadas para os alunos com necessidades educacionais especiais no âmbito do MEC, que não confrontam diretamente os processos de exclusão e marginalização solapados pelas teorias pedagógicas hegemônicas ${ }^{7}$ e pelo modo de produção capitalista.

O Censo Demográfico de $2010^{8}$ investigou os seguintes tipos de deficiência: visual, auditiva,

\footnotetext{
${ }^{5}$ A designada SECADI surgiu, por sua vez, da reestruturação realizada na ex-Secretaria de Educação Continuada, Alfabetização e Diversidade (SECAD), à qual se "acrescentou" o eixo da inclusão. (BEZERRA, 2013, p. 946).

6 Informação disponível em: <http://portal.mec.gov.br/index.php?option=com_content\&view=article\&id= 290\&ltemid=816>. Acesso em: 30 abr. 2014.

${ }^{7}$ Aqui o autor se refere às teorias não críticas - que englobam a pedagogia tradicional, a pedagogia nova e a pedagogia tecnicista - detalhadas por Saviani (1999) e que entendem a marginalidade como fenômeno pontual/acidental, que pode ser efetivamente corrigido pela educação.

8 Informações disponíveis em: <http://7a12.ibge.gov.br/voce-sabia/calendario-7a12/event/57-dia-internacional -das-pessoas-com-deficiencia>. Acesso em: 21 abr. 2015.
} 
motora e mental/intelectual. Os resultados revelam que, no Brasil, quase $1 / 4$ da população (23,9\%) possuía algum tipo de disfunção, o que corresponde a aproximadamente 45,6 milhões de pessoas. Destas 7,5\% têm de 0 a 14 anos de idade (aproximadamente 3.459.401 de crianças e jovens), 24, 9\% de 15 a 64 anos de idade e 67,7\% têm mais de 65 anos de idade ${ }^{9}$. Em relação à escolarização, a pesquisa indica que 95,1\% das crianças (entre 06 a 14 anos de idade) com deficiência frequentavam a escola. Outro dado importante, diz respeito às taxas de alfabetização, que ficaram em torno de 90,6\% quando consideramos a população em geral e $81,7 \%$ quando falamos das pessoas com qualquer uma das quatro categorias elencadas pelo IBGE (2011).

Segundo registros do Censo Escolar 2013, houve um aumento de 2,8\% no número de matrículas na modalidade educação especial, que passou de 820.433 em 2012 para 843.342 em 2013. Quanto o número de alunos incluídos em classes comuns do ensino regular e na Educação de Jovens e Adultos (EJA), o aumento foi 4,5\%. Destas matrículas, $78,8 \%$ são em escolas públicas e $21,2 \%$ em escolas privadas (INEP, 2014).

A matrícula de alunos com NEEs nas escolas/classes especiais, por sua vez, apresentou quedas consideráveis, com variação negativa de 2,6\% no período que vai de 2012 a 2013. Já nas escolas de ensino regular e salas comuns ocorreu exatamente o contrário, já que tivemos aumentos contínuos nas matrículas, com variação positiva de 4,5\% entre 2012 e 2013 e um aumento superior a 100\% entre 2007 e 2013.

Confrontando os dados do Censo Demográfico 2010 com as informações do Censo Escolar 2013, estimamos que existem por volta de 2 milhões de crianças e jovens com necessidades educacionais especiais fora da escola. Questão problemática, tendo em vista os princípios presentes na legislação específica, que advogam a universalização do acesso à formação básica e a inclusão total do público-alvo da educação especial nas salas regulares.

De acordo com Garcia e Michels (2011) neste início de século XXI, a política de educação especial assume uma perspectiva marcadamente inclusiva, estabelecendo uma relação mais definida com a educação básica. Este movimento vem sendo incrementado no bojo das iniciativas de expansão do atendimento aos alunos com necessidades educacionais especiais, notadamente a partir do segundo mandato do Governo Lula (2007-2010).

Contudo, como vimos nos dados apresentados, uma série de desafios ainda precisam ser enfrentados no que se refere ao acesso e à permanência de estudantes com deficiências, transtornos

\footnotetext{
${ }^{9} \mathrm{O}$ que se articula com o processo de envelhecimento da população e com a consequente perda de funcionalidade em virtude de doenças adquiridas.
} 
globais do desenvolvimento e altas habilidades/superdotação na educação básica e no ensino superior (BRASIL, 2008).

O mais recente Plano Nacional de Educação, aprovado pela Lei 13.005 de 25 de junho de 2014, expressa a preocupação da esfera federal com a estruturação da educação especial na perspectiva inclusiva, em consonância com a legislação nacional sobre o tema e com a agenda internacional, firmada pelas agências multilaterais nas conferências realizadas ao longo da década de 1990.

Entre as diretrizes do PNE contempladas em seu art. 2ำ temos: I - erradicação do analfabetismo; II - universalização do atendimento escolar; III - superação das desigualdades educacionais, com ênfase na promoção da cidadania e na erradicação de todas as formas de discriminação; IV melhoria da qualidade da educação; $V$ - formação para o trabalho e para a cidadania, com ênfase nos valores morais e éticos em que se fundamenta a sociedade; VI - promoção do princípio da gestão democrática da educação pública; VII - promoção humanística, científica, cultural e tecnológica do país; VIII - estabelecimento de meta de aplicação de recursos públicos em educação com proporção do Produto Interno Bruto (PIB), que assegure atendimento às necessidades de expansão, com padrão de qualidade e equidade; IX - valorização dos (as) profissionais da educação; X-promoção dos princípios do respeito aos direitos humanos, à diversidade e à sustentabilidade socioambiental (BRASIL, 2014).

A Meta 4, que trata especificamente da educação especial, defende o acesso dos alunos com necessidades educacionais especiais à formação básica e ao AEE "preferencialmente na rede regular, com recursos multifuncionais e serviços especializados públicos e conveniados" (SAVIANI, 2014, p. 04). Em seguida, elenca 19 estratégias voltadas para o fortalecimento de um sistema educacional inclusivo. Entre os aspectos centrais sugeridos pelo PNE 2014-2024 (BRASIL, 2014), destacamos:

- Universalização do atendimento escolar às crianças e jovens de 0 a 17 anos de idade com deficiência, transtornos globais do desenvolvimento e altas habilidades/superdotação;

- Implantação gradual de Salas de Recursos Multifuncionais (SRMs) e formação continuada de professores para o AEE nas escolas urbanas, do campo, indígenas e de comunidades quilombolas;

- Estímulo à criação de centros multidisciplinares de apoio, pesquisa e assessoria, integrando profissionais de diferentes áreas que possam amparar o trabalho dos professores da educação básica, responsáveis pela educação especial;

- Ampliação dos programas suplementares que promovam a acessibilidade nas instituições públicas, garantindo o acesso e permanência dos alunos com necessidades educacionais especiais nas escolas regulares;

- Articulação pedagógica entre o ensino regular e o AEE;

- Incentivo às pesquisas voltadas para o desenvolvimento de metodologias, materiais didáticos, 
equipamentos e tecnologias assistivas, com vistas à promoção do ensino e da aprendizagem e à formulação de políticas públicas intersetoriais no campo da educação especial;

- Oferta de educação bilíngue, em Língua Brasileira de Sinais - LIBRAS (como primeira língua) e Língua Portuguesa aos alunos surdos e/ou com deficiência auditiva ${ }^{10}$, bem como a adoção do Sistema Braille de leitura para cegos e surdos-cegos;

- Capacitação e ampliação do número de profissionais envolvidos no atendimento aos alunos com necessidades educacionais especiais, incluindo professores de AEE, profissionais de apoio ou auxiliares, tradutores e intérpretes de LIBRAS, guias-intérpretes para surdos-cegos, professores de LIBRAS (prioritariamente surdos) e professores bilíngues;

- Obtenção de informações detalhadas sobre o perfil das pessoas com deficiência, transtornos globais de desenvolvimento e altas habilidades/superdotação, sistematizadas por meio da parceria entre órgãos de pesquisas e estatística e o MEC;

- Incentivo à abordagem de temas relativos à inclusão de alunos com necessidades educacionais especiais e ao AEE nos cursos de licenciatura e formação de profissionais da educação;

- Promoção de parcerias com instituições comunitárias, confessionais e filantrópicas sem fins lucrativos, conveniadas com a esfera governamental, objetivando: o apoio integral ao públicoalvo da educação especial matriculado nas escolas da rede pública; a formação continuada de professores; a elaboração de material didático acessível; a disponibilização de recursos e serviços de acessibilidade; e a participação das famílias e da sociedade na construção do sistema educativo inclusivo.

Segundo dados disponibilizados pelo Observatório do PNE ${ }^{11}$, as matrículas dos alunos com necessidades educacionais especiais em escolas regulares, entre 2007 e 2013 subiram de 306.136 para 648.921 (aumento de 112\%). Em 2013, 76,9\% desses estudantes estavam frequentando as salas comuns, sinalizando um rompimento com o histórico processo de exclusão em espaços segregados. Entretanto, na prática, inúmeras barreiras têm sido enfrentadas pelas escolas, pelos professores e pelos sistemas de ensino, no que se refere à inclusão efetiva dos educandos com necessidades especiais nos estabelecimentos da rede pública.

A produção científica na área é relativamente extensa, tendo em vista a relevância que a temática adquiriu nas últimas décadas e as exigências trazidas pela escola e pela sociedade civil, no que diz respeito à promoção de articulações entre teoria e prática. Alguns autores como Garcia (2006 e 2013), Kassar $(2011,2012)$, Michels $(2002,2006)$ e Prieto (2006) têm discutido os problemas que as crianças e jovens com desenvolvimento atípico enfrentam em sua incursão na escola regular, alertando-nos sobre a "insuficiência das proposições inclusivas para as políticas de educação especial no Brasil no sentido da superação das desigualdades educacionais" (GARCIA, 2006, p. 314). Destacam

\footnotetext{
${ }^{10}$ Nos termos do art. 22 do Decreto 5.626 de 22 de dezembro de 2005 e dos arts. 24 e 30 da Convenção sobre os Direitos das Pessoas com Deficiência (2006).

11 Informação disponível em: <http://www.observatoriodopne.org.br/metas-pne/4-educacao-especial-inclu siva>. Acesso em: 08 abr. 2015.
} 
também que a política de inclusão escolar não consiste apenas na permanência física dos alunos com necessidades educacionais especiais junto aos demais educandos, mas propõe um novo olhar sobre a diferença, levando-nos a rever nossas concepções, reformular paradigmas, democratizar recursos e combater preconceitos historicamente alicerçados.

Conforme Silva (2013), nos últimos anos as classes e escolas especiais, privadas e filantrópicas, vem sendo substituídas pelas salas de recursos, ainda que de forma precária. $O$ fato é que persistem formas de exclusão dentro da escola regular que impedem que os alunos com necessidades educacionais especiais atinjam as metas escolares previstas para todos os estudantes. Outro ponto a ser destacado refere-se à restrição do AEE apenas ao trabalho que é desenvolvido nas SRMs, o que sugere formas veladas e/ou mais sutis de segregação desses estudantes.

Como vimos no detalhamento do PNE 2014-2024 (BRASIL, 2014), entre os aspectos centrais a serem trabalhados nesta época de "políticas inclusivas" estão a questão da acessibilidade (arquitetônica e comunicacional, entre outras); a formação e capacitação profissional; e os problemas estruturais, decorrentes da ausência de materiais/serviços de apoio pedagógico especializado. De fato, são muitas as dificuldades encontradas na efetivação de uma verdadeira educação inclusiva - tal como vem sendo definida pela legislação e pelos estudiosos da área.

De acordo com Prieto (2006, p. 45), a política educacional brasileira tem deslocado progressivamente para os municípios parte da responsabilidade "administrativa, financeira e pedagógica pelo acesso e permanência de estudantes com necessidades educacionais especiais, em virtude do processo de municipalização do Ensino Fundamental". Isso exige esforço redobrado por parte das Secretarias Municipais de Educação, como forma de atender às especificidades dessa clientela - sobretudo na faixa etária que vai dos 0 aos 06 anos de idade - investindo também na formação e capacitação de educadores para o trabalho em contextos inclusivos. Evidentemente, muitas cidades enfrentam barreiras para garantir a qualidade do atendimento educacional oferecido, o que amplia as estatísticas sobre a exclusão/marginalização de alunos com deficiências, transtornos globais do desenvolvimento e (eventualmente) altas habilidades/superdotação.

Outro impedimento se refere ao caráter essencialmente contraditório das políticas públicas brasileiras no campo da educação, que privilegiam resultados em detrimento da qualidade. De um lado há os ajustes estruturais (característicos do arranjo neoliberal) e as desigualdades regionais no que se refere aos investimentos financeiros - quase sempre insuficientes para dar conta das particularidades dos educandos com necessidades educacionais especiais e dos problemas enfrentados pelas 
escolas. Do outro, verifica-se um aumento significativo no número de matrículas, decorrentes da "universalização" do acesso e da obrigatoriedade da oferta da educação especial, como componente que perpassa todos os níveis, etapas e modalidades de ensino (KASSAR, 1998; MICHELS, 2006).

Fica claro que o governo federal estabelece uma série de propostas de longo alcance, desconsiderando as reais capacidades do Estado para suprir as demandas e carências do público-alvo do AEE. Daí a ideia de transferir para a iniciativa privada ${ }^{12}$ algumas responsabilidades, garantindo assim o alcance dos objetivos previstos no PNE. Trata-se, sem dúvida, de uma lógica perigosa, uma vez que os interesses desse setor - relacionados ao lucro e à competitividade - diferem, em boa parte dos interesses do Estado (ou do que deveriam ser os interesses do Estado). O resultado final acaba sendo uma diminuição dos valores a serem disponibilizados e aplicados por aluno ${ }^{13}$, um enfraquecimento dos princípios defendidos pelas políticas inclusivas e um consequente déficit na qualidade da educação oferecida. Sem dúvida, uma equação difícil de resolver. Desta forma

\begin{abstract}
se a "educação para todos" é a máxima para a educação, a integração é o preceito da educação especial. Como no Ensino Fundamental, o "fio condutor" das políticas para a área também tem como slogan "educação para todos". Entretanto, esse princípio sofre as restrições de uma política que privatiza os serviços públicos, altera a função do Estado, promove a autonomia escolar, constrói estreito modelo de cidadania, prioriza o Ensino Fundamental em detrimento de outros níveis, implementa um sistema de avaliação acentuadamente quantitativo, define os conhecimentos, valores e atitudes que respondem às imposições do mercado e busca o consenso como forma de adesão a seu projeto político. Caudatária dessas limitações, a política para a educação especial revela-se segregacionista (MICHELS, 2002, p. 79).
\end{abstract}

Garcia (2004) e Barroco (2011) mencionam o empobrecimento curricular que acompanha o trabalho pedagógico nas escolas inclusivas, impedindo o pleno acesso dos alunos com necessidades educacionais especiais ao conhecimento historicamente elaborado. Isso ocorre quando os professores promovem reformulações no currículo, ora eliminando conteúdos essenciais, ora abordando-os de forma incompleta.

O ceticismo quanto à apropriação dos saberes clássicos/científicos pelo público-alvo da educação especial pode ser observado no trecho abaixo, retirado do documento Estratégias para a Educação de Alunos com Necessidades Educacionais Especiais, divulgado pelo MEC em parceria com a

\footnotetext{
12 Lembramos que o setor privado tem um longo histórico de atuação no campo da educação especial, fundamentada na segregação e na filantropia, questões que já foram problematizadas pela legislação nacional no campo da inclusão e em uma série de pesquisas sobre o tema (KASSAR, 2011).

13 Para mais informações ver: AMARAL, N. C. Brasil e o novo PNE: expansão-qualidade-financiamento. Disponível em: <http://www.anpae.org.br/seminario/ANPAE2012/Textos/NelsonAmaral.pdf>. Acesso em: 10 jan. 2016.
} 
Secretaria de Educação Especial (SEESP) em 2003:

Embora muitos educadores possam interpretar essas medidas como "abrir mão" da qualidade do ensino ou empobrecer as expectativas educacionais, essas decisões curriculares podem ser as únicas alternativas possíveis para os alunos que apresentam necessidades especiais como forma de evitar a sua exclusão (BRASIL, 2003, p. 38).

O texto, de fato, valida o rebaixamento das expectativas escolares de crianças/jovens com deficiências e outros distúrbios que, em virtude de suas limitações, são considerados inaptos ou parcialmente aptos para aprender e desenvolver as habilidades/competências exigidas pela escola - o que os impede de acessar os níveis mais elevados de ensino. Sendo assim, ao mesmo tempo que chama a atenção para o direito dos sujeitos "excluídos" à escola, o discurso em defesa da diversidade acaba operando por meio de um acesso desigual à cultura humana (GARCIA, 2004).

Aprofundando um pouco mais a crítica, concluímos que as políticas inclusivas podem ser aproximadas das bases funcionalistas de compreensão da sociedade, vinculadas à manutenção da ordem vigente (GARCIA, 2004, p. 190), o que sugere não a transformação, mas a "simples administração das desigualdades por meio de encaminhamentos politicamente corretos". Nesse sentido, a concepção de NEEs não supera as proposições de natureza medico-clínica, uma vez que também opera por diagnósticos, responsabilizando os sujeitos, individualmente, por suas dificuldades, além de impedilos de se apropriarem (integralmente) do conhecimento em sua forma elaborada (BARROCO, 2011; MARSIGLIA, 2012).

A discussão em torno da flexibilização curricular, do rebaixamento das expectativas escolares e da reformulação das estratégias de ensino direcionadas aos alunos com necessidades educacionais especiais contribui assim, de acordo com a pedagogia histórico-crítica14, para o fortalecimento das desigualdades dentro da própria escola e para a ampliação da chamada inclusão excludente (KUENZER, 2005) ou exclusão branda (FREITAS, 2002), fundamentadas no acesso desigual dos sujeitos ao conhecimento. Tais processos se efetivam quando o aluno permanece na escola regular, mesmo sem aprender, ao contrário do que ocorria anteriormente, quando era eliminado (em virtude de sucessivas reprovações) ou tinha seu acesso às salas comuns vetado pelos sistemas de ensino.

O que ocorre é que, em nome do reconhecimento das diferenças são propostos mecanismos de flexibilização curricular, ou seja, o empobrecimento e o rebaixamento das exigências escolares, uma

\footnotetext{
${ }^{14}$ Fundamentada no materialismo histórico-dialético e na psicologia histórico-cultural, a proposta sugere uma ruptura fundamental em relação às teorias pedagógicas não críticas e crítico-reprodutivistas, reconhecendo as potencialidades emancipadoras da ação educativa que, deve obrigatoriamente, confrontar a lógica neoliberal, o neopragmatismo e as formas de alienação decorrentes do modo de produção capitalista (SAVIANI, 2013).
} 
vez que os currículos podem ser reduzidos com base nas dificuldades dos alunos e, mesmo assim, ser considerados como parte do processo de inclusão educacional. Nesse caso, numa mesma escola, na mesma classe, alunos identificados como "diferentes" podem aprender menos que os outros (GARCIA, 2004, p. 197).

Para Garcia (2004) e Michels (2006), inclusão e exclusão são condições inerentes às relações sociais desiguais que constituem a sociedade capitalista. Nesse sentido, a interpretação da realidade deve levar em conta as tensões presentes nessa articulação entre os dois conceitos. No que se refere às políticas inclusivas, as autoras destacam as inúmeras contradições envolvidas no processo de formulação e legitimação das bases legais/normativas, tanto nas escolas como em outros espaços de ensino-aprendizagem. Aprofundaremos algumas dessas questões em nosso próximo tópico.

\section{Neoliberalismo e Políticas Educacionais Inclusivas - O Não Dito e o Mal Dito}

A partir da década de 1990, no contexto mais amplo da reforma do Estado, a educação passa a ser considerada fator determinante na reestruturação produtiva e no acirramento da competitividade entre os países. Nesse período temos "uma reforma da administração pública no sentido de torná-la menos burocrática e mais gerencial” (GARCIA, 2004, p. 36), lançando mão de algumas estratégias como a descentralização administrativa (e a consequente corresponsabilização e redistribuição de competências entre União, Estados e Municípios); e o enfoque na eficiência, na focalização e na redução de custos, além da preocupação com a qualidade dos serviços ofertados e com o controle dos resultados. Nos países em desenvolvimento, concretiza-se a concepção de estado mínimo. Para a efetivação de tal proposta, as nações latino-americanas (entre elas o Brasil) contam com a colaboração das diversas esferas de governo e das organizações da sociedade civil (SHIROMA, MORAES; EVANGELISTA, 2011; TORRES, 2002).

O modelo neoliberal15 que fundamenta as reformas da década de 1990, sugere a diminuição da participação financeira do Estado no fornecimento de serviços sociais - incluindo educação, saúde, pensões/aposentadorias, transporte público e habitação - e sua subsequente transferência para o setor privado. Essa é uma das consequências do chamado ajuste estrutural, que almeja, entre outras coisas, a diminuição dos gastos públicos e o aumento da produtividade/competitividade interna. Vasta documentação internacional, elaborada por organismos multilaterais, como a UNESCO, o BM, a OCDE

\footnotetext{
${ }^{15}$ Na perspectiva de Kassar (1998), o neoliberalismo é uma reação teórica e política veemente contra o Estado intervencionista e de bem-estar social, que tem como bases fundamentais a liberdade individual, a livre concorrência e a desigualdade estrutural.
} 
e a CEPAL disseminam esse ideário mediante diagnósticos, estudos, análises e propostas considerados(as) adequados(as) para todos os países da América Latina, tanto no campo educação quanto no da economia (FRIGOTTO, 2002; SHIROMA, MORAES; EVANGELISTA, 2011; SILVA, 2014).

De acordo com Michels (2006, p. 410), a reforma educacional no Brasil abarca alguns pontos cruciais como "a gestão, o financiamento, a avaliação, a formação dos professores, o currículo e a inclusão". Um dos marcos importantes desse período foi justamente o Plano Decenal de Educação (previsto para vigorar de 1993 a 2003), cujas bases foram lançadas pela Conferência Mundial de Educação para Todos (UNESCO, 1990) - que sugeria a formulação de políticas de apoio à educação no âmbito econômico, social e cultural; a mobilização de recursos financeiros, públicos e privados no alcance de metas educacionais até o ano 2000; e o fortalecimento da solidariedade internacional na expansão da oferta do ensino de caráter universalizante.

Ainda em 1990, o documento Transformacion productiva com equidad, organizado pela CEPAL, recomendava que os países da América Latina investissem nas reformas dos seus sistemas educativos, objetivando o desenvolvimento extensivo de conhecimentos/habilidades exigidos(as) pelo sistema produtivo, como a versatilidade, a capacidade de inovação, a comunicação e a flexibilidade para adaptar-se às novas tarefas. Já em 1992, o documento Educácion y conocimento: eje de la transformácion productiva com equidade, decorrente da parceria entre CEPAL e UNESCO, defendia a reforma dos sistemas educacionais, a capacitação profissional, em articulação com as concepções de cidadania, competitividade, equidade, eficiência, integração nacional e descentralização (SHIROMA; MORAES; EVANGELISTA, 2011).

É importante salientar o papel fundamental do Banco Mundial, que promoveu, ao longo da década de 1990, investimentos em áreas estratégicas, financiando políticas educacionais e sociais nos países em desenvolvimento. A instituição internacional conta com 176 países mutuários, inclusive o Brasil. Entretanto apenas 5 definem, prioritariamente as ações que serão implementadas: EUA, Japão, França, Alemanha e Reino Unido. Em 1993, o BM publica o documento Prioridades y Estratégias para la Educación, que tem como propostas a eliminação do analfabetismo; a racionalização dos recursos financeiros e gerenciais; o estreitamento dos laços entre o ensino e o setor produtivo; a qualidade e eficiência na formação profissional (SHIROMA; MORAES; EVANGELISTA, 2011). Obviamente, essa entidade internacional almeja retornos financeiros a médio/longo prazo, decorrentes dos empréstimos a juros. A preocupação com as taxas de retorno dos investimentos, logo, supera o interesse pela qualidade das ações e serviços educacionais financiados em cada localidade.

Outro ponto a ser mencionado é o alinhamento dos objetivos educacionais veiculados pelas 
agências multilaterais às exigências do mercado, almejando a formação básica do cidadão produtivo, tendo como referência a Teoria do Capital Humano (TCH).

\begin{abstract}
Em suma, o Banco Mundial recomenda mais atenção aos resultados, sistema de avaliação da aprendizagem, inversão em capital humano atentando para a relação custo-benefício; propõe além da descentralização da administração das políticas sociais, maior eficiência no gasto social, maior articulação com o setor privado na oferta da educação (SHIROMA; MORAES; EVANGELISTA, 2011, p. 62).
\end{abstract}

Nessa perspectiva, podemos dizer que a intervenção das agências reguladoras internacionais no financiamento dos programas educacionais no Brasil é marcadamente contraditória. Ao mesmo tempo em que incentivam determinadas ações pontuais e oferecem apoio financeiro, organizações como o Banco Mundial e o Fundo Monetário Internacional (FMI) contribuem para o endividamento dos países em desenvolvimento, para a manutenção da hierarquia entre ricos (que são os detentores do capital em escala global) e pobres (que tomam grandes empréstimos como forma de elevar a qualidade dos seus serviços essenciais) e para o fortalecimento das relações de dependência estrutural (FONSECA, 2002; FRIGOTTO, 2002). Lembremos que algumas cláusulas contratuais previstas nesses acordos internacionais, recomendam o ajuste da conduta econômica dos países devedores, por meio de adoção de práticas voltadas para o livre mercado.

Como mencionamos anteriormente, de acordo com a Política Nacional de Educação Especial na Perspectiva da Educação Inclusiva (BRASIL, 2008), a educação especial deve ser objeto de uma política educacional de igualdade concreta, reconhecida como parte integrante dos direitos humanos em conformidade com os tratados internacionais - e como componente fundamental na capacitação para a cidadania democrática. Com base nesses argumentos, Garcia (2004) ressalta a importância da análise das políticas de inclusão como processo permeado por conflitos de interesse e embates entre diferentes visões e projetos - o que pode ser exemplificado por meio das relações entre público e privado.

O atendimento direcionado aos alunos com necessidades educacionais especiais dependeu, durante muito tempo, da atuação de instituições de apoio e assistência gerenciadas por particulares, com ou sem suporte técnico/financeiro do Estado. Seguindo a mesma linha de raciocínio, Kassar (1998, n.p.) ressalta que a concomitância dos setores público/privado no campo da educação especial caracteriza a própria trajetória desta modalidade de ensino, haja vista o histórico descaso dos governos com a formação escolar dos deficientes. Segundo a autora, o discurso inclusivo tem, assim, sustentação no pensamento liberal, cujos princípios fundam-se 


\begin{abstract}
sobre a crença na evolução "natural" da sociedade e no desenvolvimento livre das potencialidades "naturais" do indivíduo. Podemos dizer que, atualmente, esse discurso encontra sustentação no pensamento neoliberal, que preconiza a organização autônoma da população na formação de associações privadas, de tal modo que estas, ao se responsabilizarem por serviços de atendimento de setores da sociedade, através de ações (assistenciais, filantrópicas, comunitárias) de "parceria", colaboram para o afastamento gradativo do Estado da responsabilidade sobre várias questões (obrigações) sociais (daí a força das instituições privadas).
\end{abstract}

Cabe salientar o papel que as agências multilaterais desempenham na formulação de diretrizes gerais, que norteiam o trabalho com público-alvo da educação especial no Brasil. As proposições atuais no campo da inclusão educacional devem ser, segundo Garcia (2004), compreendidas como parte de uma política educacional que se articula com as exigências econômicas internacionais, referenciadas em uma série de conceitos e slogans como "equidade", "autonomia", "diversidade", "necessidades básicas de aprendizagem"16, "cidadania ativa", "tolerância", entre outros. Por meio de uma agenda globalmente estruturada, os interesses do Estado neoliberal são assim conciliados com as "reivindicações dos movimentos sociais de e para deficientes" (SILVA, 2014, p. 81).

Como já destacamos, a política educacional brasileira em nossos dias, apoia-se no paradigma da inclusão total, demarcando seu compromisso com a valorização da diversidade, em todas as suas manifestações (BRASIL, 2008). Contudo, os mecanismos de que dispõe para reduzir a exclusão escolar não superam os elementos que geram as desigualdades educacionais, e que estão vinculados à dinâmica social estabelecida.

[...] observa-se que as políticas de inclusão podem ser aproximadas de bases funcionalistas de compreensão da sociedade, vinculando-se à manutenção da ordem vigente. Nestes termos, pode-se afirmar que o modelo nacional de educação inclusiva, no que se refere à educação especial, converge para administrar, justificar e legitimar as desigualdades sociais e educacionais numa lógica de mercado (GARCIA, 2004, p. 190).

Considerando os apontamentos trazidos por Freitas $(2002,2007)$, Michels $(2006$, p. 420) associa as reformas da década de 1990 às formas de ocultação da exclusão social (próprias do modelo neoliberal), no qual o fracasso escolar - que acompanha alguns grupos marginalizados como os alunos com necessidades educacionais especiais - passa a ser explicado com base nas diferenças individuais. Nesse contexto, a culpa recai sobre o próprio excluído, o que faz da inclusão um processo essencialmente perverso, que não contribui para o real combate às desigualdades sociais e ainda "celebra a

\footnotetext{
${ }^{16}$ Retomando o conceito presente na Declaração Mundial Sobre Educação para Todos (UNESCO, 1990).
} 
diferença que exclui". A terminologia reformista e os princípios "inclusivos" disseminados pelas agências multilaterais ${ }^{17}$ - e materializados pelas políticas públicas focalizadas - acabam, assim, por ocultar as várias formas de exploração e exclusão dos grupos marginalizados, bem como as desigualdades decorrentes do modo de produção capitalista. Seguindo essa linha de raciocínio, a sociedade inclusiva

[...] é aquela que apresenta compromissos e propósitos comuns e que se esforça para envolver todos os seus cidadãos no mercado de trabalho, associações da sociedade civil, no processo político, desenvolvendo um sentido de responsabilidade. Esse discurso expressa uma concepção de sociedade harmônica e de cooperação, apesar das visíveis condições de desigualdade social. Expressa também a necessidade desse projeto em divulgar a importância da formação de consensos em face à dinâmica conflituosa da sociedade capitalista (GARCIA, 2004, p. 128).

De acordo com Marsiglia (2012, p. 119), o relativismo cultural e o pragmatismo, presentes nos discursos das agências multilaterais, imprime uma atitude de fragmentação dos indivíduos, atendendo assim, aos interesses capitalistas, "que necessitam do esfacelamento do reconhecimento dos humanos como membros do gênero humano para naturalizar as relações de exploração e dominação". Inclusão/exclusão emergem, pois, como elementos constitutivos das relações sociais desiguais que gerem a sociedade capitalista (FREITAS et al., 2004; MICHELS, 2006). Desta forma, a marginalização e a alienação não são, de fato, percebidas como históricas, logo, passíveis de serem modificadas.

Garcia (2004) argumenta que o discurso em defesa da diversidade, ao mesmo tempo que chama a atenção para o direito à educação dos sujeitos excluídos, acaba contribuindo para um acesso desigual à cultura humana - processo que decorre das flexibilizações e adaptações curriculares que caracterizam o trabalho pedagógico com o público-alvo da educação especial. Aprofundando a crítica, a autora destaca que

a proposição inclusiva se constitui de parâmetros classificatórios meritocráticos, cujos processos participam na definição de forma e quantidade em relação às aprendizagens dos alunos, diferenciando por consequência quem pode aprender mais e menos. Os princípios liberais que sustentam essa compreensão de desenvolvimento se apoiam no reconhecimento da diferença, na dignidade humana, na promoção da cidadania. Mas é possível perceber nesses propósitos a marca da desigualdade, embora constituída de encaminhamentos "politicamente corretos". O discurso da diversidade, ao mesmo tempo que chama a atenção para o direito à educação dos sujeitos "excluídos", está

\footnotetext{
17 Garcia (2004, p. 151), ressalta algumas peculiaridades no discurso das agências multilaterais. "A OCDE coloca sua ênfase na comunidade como o grande sujeito social; o Banco Mundial centra seus argumentos sobre uma abordagem de proteção social; a UNESCO assume o argumento que coloca a educação no centro do processo de resolução das questões sociais, principalmente na conformação de uma cidadania adequada aos novos tempos. A CEPAL compartilha das ideias e proposições presentes nos demais documentos, utilizando-se dos mesmos conceitos [...]".
} 
Nesse sentido, a preocupação superficial com a "igualdade entre todos" e com o "respeito a diversidade" acaba por atender aos interesses econômicos, impedindo que as desigualdades sejam reveladas em toda a sua amplitude. Em Freitas et al (2004, p. 65) vemos que "uma inclusão real só será possível quando uma outra sociedade for possível". Daí a necessidade de uma abordagem teórica contra hegemônica, que ofereça subsídios para a transformação social, o que sugere a superação da lógica do capital, dentro e fora da escola (SAVIANI, 1999).

Destacamos o mérito da teoria histórico-cultural como componente indutor de uma nova postura diante das diferenças. Na perspectiva vigotskiana, as leis do desenvolvimento são as mesmas para todas as crianças. Os processos de socialização e instrução é que variam. Nesse contexto, a criança cujo percurso está complicado por um "defeito" não é menos desenvolvida que seus parceiros "normais", mas desenvolvida de outro modo. Tal constatação nos remete à importância da instrução programada (que tem a escola como lócus de materialização) e das apropriações culturais, como ferramentas capazes de promover o avanço das funções mentais superiores. Estas, por sua vez, estruturamse a partir de processos de mediação do conhecimento, que possibilitem a inteligibilidade do real em suas múltiplas determinações (BARROCO, 2011; VIGOTSKI 2011a, 2011b).

Por fim, enfatizamos as contribuições da pedagogia histórico-crítica como teoria apta a confrontar as desigualdades e as diferentes formas de exclusão, engendradas pelo modo de produção capitalista. Para Saviani (2011, 2013), o domínio da cultura historicamente produzida é condição indispensável para a participação política das massas. A ruptura em relação à lógica neoprodutivista e neotecnicista (FREITAS, 2012; SAVIANI, 2011) demanda uma reflexão coletiva sobre as concepções de ser humano, educação, sociedade e conhecimento que têm fundamentado as políticas públicas e as práticas educativas na atualidade.

Silva (2014, p. 85) destaca que as "contribuições da pedagogia histórico-crítica para a educação especial brasileira estão nos pressupostos filosóficos, na proposta pedagógico-metodológica e no significado político da sua realização [...]". Em síntese, a teoria aponta para a defesa de uma formação de qualidade para todos, que se comprometa com a superação das formas de exclusão, marginalização e alienação que caracterizam nossa sociedade, tendo como meta a superação das desigualdades de classe e a transformação social, objetivamente revolucionária.

Partindo do pressuposto de que as relações sociais capitalistas transformam aquilo que seria humanização em seu oposto, ou seja, em alienação, uma teoria pedagógica essencialmente contra hegemônica, exige um claro posicionamento perante à luta de classes, objetivando a "construção de 
uma sociedade na qual os indivíduos possam desenvolver-se de forma livre e universal numa autoatividade repleta de sentido, instaurando relações humanas plenas de conteúdo" (SAVIANI, 2011, p. 222).

Barroco (2011) e Marsiglia (2012), sugerem o enfrentamento da exclusão através da socialização dos saberes clássicos e de uma ação pedagógica planejada, que considere a centralidade dos processos de instrução escolar e as potencialidades reais das pessoas com necessidades educacionais especiais - questões já discutidas por Vigotski em seus estudos sobre a Defectologia. A apropriação dos saberes produzidos coletivamente é parte dessa luta ideológica, uma vez que instrumentaliza a passagem do sujeito "em si" em direção ao sujeito "para si" (DUARTE, 2013), comprometido com a superação das formas capitalistas de exploração do homem pelo homem. Em síntese, todas as pessoas, sejam elas deficientes ou não, devem ter acesso ao conhecimento historicamente produzido pela humanidade por meio da escola, tida como espaço de formação, socialização, reflexão e resistência.

Logo, uma proposta verdadeiramente inclusiva só será possível na medida em que os mecanismos de dominação, exploração e alienação forem, efetivamente, desvelados ${ }^{18}$. Para isso, faz-se necessário ir além da defesa da diversidade em sua dimensão relativista e multiculturalista.

\section{Considerações Finais}

Segundo Prieto (2006), o planejamento e a implantação de políticas educacionais para atender alunos com necessidades educacionais especiais requerem, efetivamente, o domínio conceitual sobre a ideia de inclusão escolar e sobre sua adoção enquanto fundamento ético-político. A realização de uma educação de qualidade para todos dependerá, pois, de uma série de condições que não se encerram na simples materialização de princípios na forma de leis, resoluções e decretos. Precisamos ir além, interpretando que significados as diretrizes legais adquirem no contexto real da sua aplicação e quais as dificuldades observadas nesse processo.

Como entrevemos na Meta 4 do atual Plano Nacional de Educação (BRASIL, 2014), a idealização de um sistema educacional inclusivo demanda, entre outras coisas: a universalização do acesso à formação básica a todas as crianças e jovens com deficiências e outros distúrbios; a oferta de recursos de apoio/acessibilidade; a capacitação profissional dos docentes; os investimentos no campo da pesquisa, visando a formulação de políticas públicas intersetoriais; a parceria com instituições conveniadas com o poder público; a participação das famílias e da comunidade; e a não "exclusão do ensino

\footnotetext{
18 Para aprofundamento da temática referente às contribuições da pedagógica histórico-crítica para a educação especial brasileira ver Silva (2014).
} 
regular, sob alegação de deficiência" (SAVIANI, 2014, p. 24). Cabe-nos, enfim, averiguar em que medida temos avançado nesse caminho, marcado por tantos tropeços e percalços.

Concluímos, logo, que o dilema central das escolas inclusivas está, justamente, na superação do pensamento determinista, que impõe limites ao desenvolvimento das potencialidades da pessoa com biotipo incomum. Precisamos, ademais, problematizar qual o real significado dessa inserção na sociedade e no mundo do trabalho, dentro dos limites de perpetuação do sistema capitalista e das desigualdades de classe.

A partir das discussões apresentadas averiguamos que o rompimento em relação às teorias pedagógicas hegemônicas exige uma reflexão detalhada sobre as bases ideológicas que têm direcionado as políticas educacionais no Brasil. Daí a necessidade de pensar sobre o papel que a escola vem assumindo na contemporaneidade na manutenção/reprodução da exclusão e no acirramento das desigualdades sociais (SILVA, 2014). Nesse sentido, convém ponderar em que medida o trabalho educativo pode se converter em prática de humanização e superação da alienação que marca as relações capitalistas de produção (SAVIANI, 2013).

Entendemos que os desafios enfrentados pela educação especial no Brasil, pouco diferem daqueles enfrentados pelo sistema educacional como um todo, em seus diversos níveis e modalidades. Por esse ângulo, mais do que a matrícula nas escolas regulares, é importante que os alunos com deficiências, transtornos globais do desenvolvimento, altas habilidades/superdotação e quaisquer outros distúrbios tenham as mesmas oportunidades que os sujeitos considerados "normais" podendo, inclusive, alcançar os níveis mais elevados de ensino e ter acesso ao conhecimento em sua forma elaborada.

A agenda dos reformadores empresariais (FREITAS, 2012) e das agências multilaterais revelase, a nosso ver, incompatível com uma proposta de educação verdadeiramente inclusiva, que favoreça o processo de humanização, o respeito às diferenças e a formação de sujeitos críticos. Reiteramos, enfim, a centralidade do debate sobre a formação humana, numa perspectiva histórico-ontológica, tendo como meta a construção de uma nova sociedade, que garanta a todos, sem qualquer distinção, condições equivalentes de desenvolvimento e aprendizagem.

\section{Referências}

AMARAL, N. C. Brasil e o novo PNE: expansão-qualidade-financiamento. Seminário da ANPAE CentroOeste e IX Seminário da ANPAE - Seção Goiás, 7. ANPAE, 2012, p. 1-14. Disponível em: <http://www.anpae.org.br/seminario/ANPAE2012/Textos/NelsonAmaral.pdf>. Acesso em: 10 jan. 2016. 
BARROCO, S. M. S. Pedagogia histórico-crítica, psicologia histórico-cultural e educação especial: em defesa do desenvolvimento da pessoa com e sem deficiência. In: MARSIGLIA, A. C. G. (Org.), Pedagogia histórico-crítica: 30 anos. Campinas: Autores Associados, 2011. p. 169-196.

BEZERRA, G. F. Tensões e contradições na política nacional de inclusão escolar: sobre a SECADI. VIII Encontro da Associação Brasileira de Pesquisadores em educação especial, Londrina, 2013, p. 945958. Disponível em: <http://www.uel.br/eventos/ congressomultidisciplinar/pages/arquivos/anais/2013/AT02-2013/AT02-001.pdf>. Acesso em 30 maio 2015.

BRASIL. Ministério de Educação. Lei no 9.394 de 20 de dezembro de 1996. Estabelece as Diretrizes e Bases da Educação Nacional. Brasília: MEC, 1996.

BRASIL. Ministério da Educação. Estratégias para a educação de alunos com necessidades educacionais especiais. Brasília: MEC/SEE, 2003.

BRASIL. Decreto 5.626 de dezembro de 2005. Regulamenta a Lei $n^{\circ} 10.436$, de 24 de abril de 2002, que dispõe sobre a Língua Brasileira de Sinais - Libras, e o art. 18 da Lei ${ }^{\circ} 10.098$, de 19 de dezembro de 2000. Brasília. 2005. Disponível em: http://www.planalto.gov.br/ccivil_03/_ato20042006/2005/decreto/d5626.htm. Acesso em: 06 abr. 2015.

BRASIL. Ministério da Educação. Política Nacional de Educação Especial na Perspectiva da Educação Inclusiva. Brasília: MEC/SEESP, 2008.

BRASIL. Decreto 7.611 de novembro de 2011. Dispõe sobre o Atendimento Educacional Especializado e dá outras providências. Brasília: MEC, 2011. Disponível em: http://www.planalto.gov.br/ccivil_03/ _ato2011-2014/2011/decreto/d7611.htm. Acesso em: 06 abr. 2015.

BRASIL. Ministério de Educação. Lei no 12.796 de 04 de abril de 2013. Altera a Lei no 9.394, de 20 de dezembro de 1996, que estabelece as diretrizes e bases da educação nacional, para dispor sobre a formação dos profissionais da educação e dar outras providências. Brasília: MEC, 2013b. Disponível em: http://www.planalto.gov.br/ccivil_03/_ato2011-2014/2013/lei/l12796.htm. Acesso em: 06 abr. 2015.

BRASIL. Ministério da Educação. Parecer CNE/CEB no 02/2013. Dispõe sobre a possibilidade de aplicação de "terminalidade específica" nos cursos técnicos integrados ao Ensino Médio. Brasília. MEC, 2013a. Disponível em: <http://portal.mec.gov.br/index.php?option=com_content\&view=article\&id=18449:ceb-2013\&catid=323:orgaos-vinculados $>$. Acesso em: 06 abr. 2015.

BRASIL. Lei 13.005 de 25 de junho de 2014. Plano Nacional de Educação - PNE 2014-2024. Disponível em: <http://www.planalto.gov.br/ccivil_03/_Ato2011-2014/2014/Lei/L13005.htm>. Acesso em 04 jul. 2014.

DUARTE, N. A individualidade para si: contribuição a uma teoria histórico-social da formação do indivíduo. Campinas: Autores Associados, 2013.

FONSECA, M. O Banco Mundial e a educação: reflexões sobre o caso brasileiro. In: GENTILI, P. (Org.), Pedagogia da exclusão: crítica ao neoliberalismo em educação. Petrópolis: Vozes, 2002. p.169-195.

FREITAS, L. C. de. A internalização da exclusão. Educação \& Sociedade, Campinas, v. 23, n. 80, p. 299325, 2002.

FREITAS, L. C. de et al. Dialética da inclusão e da exclusão: por uma qualidade negociada e emancipadora nas escolas. In: GERALDI, C. M. G.; RIOLFI, C. R.; GARCIA; M. F. (Orgs.), Escola viva: elementos 
para a construção de uma educação de qualidade social. Campinas, SP: Mercado das Letras, 2004. p. 61-88.

FREITAS, L. C. de. Eliminação adiada: o ocaso das classes populares no interior da escola e a ocultação da (má) qualidade do ensino. Educação \& Sociedade, Campinas, v. 28, n. 100 - Especial, p. 965-987, 2007.

FREITAS, L. C. de. Os reformadores empresariais da educação: da desmoralização do magistério à destruição do sistema público de educação. Educação \& Sociedade, v. 33, p. 379-404, 2012.

FRIGOTTO, G. Os delírios da razão: crise do capital e metamorfose conceitual no campo educacional. In: GENTILI, P. (Org.) Pedagogia da Exclusão. Petrópolis: Vozes, 2002. p. 77-108.

GARCIA, R. M. C. Políticas para a educação especial e as formas organizativas do trabalho pedagógico. Revista Brasileira de Educação Especial. [online]. v.12, n.3, p. 299-316, 2006.

GARCIA, R. M. C. Política de educação especial na perspectiva inclusiva e a formação docente no Brasil. Revista Brasileira de Educação, Campinas, v. 18, n. 52, jan./mar., p. 101-119, 2013.

GARCIA, R. M. C.; MICHELS, M. H. A política de educação especial no Brasil (1991-2011): uma análise da produção do GT 15 - educação especial da ANPED. Revista Brasileira de Educação Especial, Marília, v. 17, p. 105-123, Edição Especial, mai./ago. 2011.

GARCIA, R. M. C. Políticas públicas de inclusão: uma análise no campo da educação especial brasileira. 2004. 216 f. Tese (Doutorado). Universidade Estadual de Santa Catarina, Florianópolis, 2004. Disponível em: <https://repositorio.ufsc.br/bitstream/handle/123456789/ 87561/202904.pdf?sequence=1>. Acesso em 14 fev. 2015.

Instituto Brasileiro de Geografia e Estatística. Censo 2010. Brasília: IBGE, 2011. Disponível em: $<$ http://7a12.ibge.gov.br/voce-sabia/calendario-7a12/event/57-dia-internacional -das-pessoas-comdeficiencia>. Acesso em: 21 abr. 2015.

INEP. Censo Escolar da Educação Básica 2013: Resumo Técnico. Brasília: INEP/O Instituto, 2014.

KASSAR, M. C. M. Liberalismo, neoliberalismo e educação especial: algumas implicações. Cad. CEDES, Campinas, v. 19, n. 46, set. 1998.

KASSAR, M. C. M. Percursos da constituição de uma política brasileira de educação especial inclusiva. Revista Brasileira de Educação Especial, Marília, v. 17, Especial, mai./ago. 2011.

KASSAR, M. C. M. Educação especial no Brasil: desigualdades e desafios no reconhecimento da diversidade. Educação \& Sociedade, Campinas, v. 33, n.120, p. 833-849, jul./set. 2012.

KUENZER, A. Z. Conhecimento e competências no trabalho e na escola. Sessão Especial "Competências em educação e formação de professores". 25a Reunião Anual da ANPED, Caxambu-MG, 2000. Disponível em: <http://www.anped.org.br/reunioes/25/ts25.htm>. Acesso em: 18 nov. 2014.

KUENZER, A. Z. Exclusão includente e inclusão excludente: a nova forma de dualidade estrutural que objetiva as novas relações entre educação e trabalho. In: LOMBARDI, J. C.; SAVIANI, D.; SANFELICE, J. L. (Orgs.), Capitalismo, trabalho e educação. Campinas: Autores Associados, 2005. p. 77-96.

MARSIGLIA, A. C. G. O tema da diversidade na perspectiva da pedagogia histórico-crítica. In: MARSIGLIA, A. C. G.; BATISTA, H. L. (Orgs.), Pedagogia histórico-crítica: desafios e perspectivas para uma educação transformadora. Campinas: Autores Associados, 2012. p. 109-146. 
MICHELS, M. H. Caminhos da exclusão: a política para a educação e a educação especial nos anos de 1990. Ponto de Vista, Florianópolis, n. 314, p. 73-86, 2002.

MICHELS, M. H.. Gestão, formação docente e inclusão: eixos da reforma educacional brasileira que atribuem contornos à organização escolar. Revista Brasileira de Educação, Campinas, v. 11, n. 33, p. 406-423, set./dez. 2006.

PRIETO, R. G. Atendimento escolar de alunos com necessidades educacionais especiais: um olhar sobre as políticas públicas de educação no Brasil. In: ARANTES, V. A. (Org.). Inclusão escolar: pontos e contrapontos. São Paulo: Summus, 2006, p. 31-73.

SAVIANI, D. Escola e Democracia. Campinas: Autores Associados, 1999.

SAVIANI, D. História das ideias pedagógicas no Brasil. Campinas: Autores Associados, 2011.

SAVIANI, D. Pedagogia histórico-crítica: primeiras aproximações. Campinas: Autores Associados, 2013.

SAVIANI, D. Plano Nacional de Educação: PNE 2014-2024. Campinas: Autores Associados, 2014.

SHIROMA, E. O; MORAES, M. C. M. de; EVANGELISTA, O. Política Educacional. Rio de Janeiro: Lamparina, 2011.

SILVA, R. H. dos R. Tendências teórico-filosóficas das teses em educação especial desenvolvidas nos cursos de doutorado em educação e educação física do Estado de São Paulo (1985-2009). 2013. Tese (Doutorado). Faculdade de Educação, Universidade Estadual de Campinas, Campinas, 2013.

SILVA, R. H. dos R. Contribuições da pedagogia histórico-crítica para a educação especial brasileira. Revista HISTEDBR Online, Campinas, n. 58, p. 78-89, set. 2014. Disponível em: < http://periodicos.sbu.unicamp.br/ojs/index.php/histedbr/article/view/8640380>. Acesso em: 14 abr. 2014.

TORRES, C. A. Estado, privatização e política educacional: elementos para uma crítica do neoliberalismo. In: GENTILI, P. (Org.) Pedagogia da Exclusão. Petrópolis: Vozes, 2002. p. 109-136.

UNESCO. Declaração Mundial sobre Educação para Todos. Conferência de Jomtien, 1990. Disponível em: <http://www.direitoshumanos.usp.br/index.php/Direito-a-Educa\%C3\%A7 \%C3\%A3\%/declaracaomundial-sobre-educacao-para-todos.html>. Acesso em 16 abr. 2015.

UNESCO. Declaração de Salamanca. Espanha, 1994. Disponível em: <http://portal.mec.gov.br/ seesp/arquivos/pdf/salamanca.pdf> Acesso em: 02 jul. 2014.

VIGOTSKI, L. S. A Defectologia e o estudo do desenvolvimento e da educação da criança anormal. Tradução: Denise Regina Sales, Marta Kohl de Oliveira, Priscila Nascimento Marques. Educação e Pesquisa, São Paulo, v. 37, n. 4, p. 861-870, dez. 2011a.

VIGOTSKI, L. S. Psicologia Pedagógica. São Paulo: Martins Fontes, 2011b.

Recebido em outubro de 2016. Aprovado em novembro de 2016. 